\title{
Organizational Structures and Processes to Support and Sustain Effective Technical Assistance in a State-wide Multi-Tiered System of Support Initiative
}

\author{
Julie Q. Morrison ${ }^{1}$, Christine Russell ${ }^{2}$, Stephanie Dyer $^{2}$, Terri Metcalf ${ }^{2}$, \& Rebecca L. Rahschulte ${ }^{3}$ \\ ${ }^{1}$ College of Education, Criminal Justice, \& Human Services, University of Cincinnati, Cincinnati, Ohio, USA \\ ${ }^{2}$ Michigan's Integrated Behavior and Learning Support Initiative, Michigan, USA \\ ${ }^{3}$ Indiana University East, Richmond, IN, USA \\ Correspondence: Julie Q. Morrison, College of Education, Criminal Justice, \& Human Services, University of \\ Cincinnati, Cincinnati, Ohio, 45221-0068, USA.
}

Received: April 23, 2014

doi:10.11114/jets.v2i3.415
Accepted: May 23, 2013 Online Published: July 1, 2014

URL: http://dx.doi.org/10.11114/jets.v2i3.415

\begin{abstract}
Despite the national proliferation of technical assistance as a driver for school reform and as a model for embedded and sustained professional development, very little is known about the organizational structures and processes needed to support technical assistance. The purpose of this paper is to describe a structured needs assessment process whereby three organizational supports were identified by technical assistance providers. The context for the provision of technical assistance was a state-wide multi-tiered system of support initiative that integrated Positive Behavioral Interventions and Supports and Response to Intervention. The results of this study are informed conceptually by the Instructional Hierarchy Model and the need to match organizational structures and processes to address the identified needs.
\end{abstract}

Keywords: Technical Assistance, Multi-tiered System of Support

\section{Introduction}

The No Child Left Behind (NCLB) Act of 2001 brought forth sweeping changes in public education driven by the expectation that all schools and school districts meet Adequate Yearly Progress in English Language Arts and mathematics. To ensure accountability to this new legislation, a series of federal sanctions and supports were designed to prioritize program improvement. Critical among these supports was the provision of technical assistance to guide state and local systems through their efforts to increase their capacity to meet students' educational needs through the diffusion of information, skills, and resources from an external technical assistance provider to a state, school district, or school levels, as established by the Technical Assistance Act of 2002 (Turnbull, White, Sinclair, Riley, \& Pistorino, 2011).

Technical assistance, as defined by the National Evaluation of the Comprehensive Technical Assistance Centers Interim Report (Turnbull et al., 2011), includes seven distinct types of activities:

(1) Ongoing consultation and follow-up through multiple service contracts over time, either to fulfill repeated requests or to follow up with individuals who participated in another assistance activity;

(2) Research collections and syntheses distributed by a Center, whether distributed by that Center or elsewhere;

(3) Engagement of participants in project planning, defined as going beyond needs assessment to include opportunities for at least some participants to shape the specific assistance;

(4) Training events, designed to impart skills and equip participants to carry out a particular program or strategy;

(5) Task force meetings and work in which a Center supported a group that was itself constituted as a task force to address a state purpose;

(6) Conferences, defined as single events in which multiple speakers or discussants presented information; and 
(7) Support for development of a formal plan to implement a program or policy, where the Center supported work by participants in a state. (Turnbull et al., 2001, p. 41)

As characterized by these seven types of activities, technical assistance is uniquely broad and fluid in nature. To be effective, technical assistance must necessarily respond to and be shaped by the contextual needs of the schools and school districts served.

Within education, technical assistance has a central role in a wide variety of educational initiatives. Yet despite the national proliferation of technical assistance as a driver for school reform and as a model for embedded and sustained professional development, very little is known about the organizational structures and processes needed to maximize the effective provision.

\subsection{The Multi-Tiered Systems of Support Framework}

The multi-tiered system of support framework is designed to meet the academic and behavioral needs of all students through the use of a continuum of instructional supports and targeted interventions of increasing intensity matched to student need. A multi-tiered system of support, such as the Positive Behavioral Interventions and Supports (PBIS) initiative, is a "decision making framework that guides the selection, integration, and implementation of the best evidence-based academic and behavioral practices for improving important academic and behavioral outcomes for all students" (OSEP Center on PBIS, 2009, p. 1). The core elements of a multi-tiered system of support include: (a) universal screening, (b) data-based decision making and problem solving, (c) continuous progress monitoring, (d) a continuum of evidence-based practices, and (e) a focus on fidelity of implementation (Sugai \& Horner, 2009). As a multi-tiered system of support, both PBIS and Response to Intervention (RTI) feature the use of data-based decision making as central and essential to meeting students' needs.

A multi-tiered system of support (MTSS) represents a fundamental shift in how educators gather, monitor, and respond to data (Daly, Martens, Barnett, Witt, \& Olson, 2007). Implementation of a MTSS requires change on many levels, with the most significant change focused on the professional practice of educators, administrators, and school-based related services professionals (Kratochwill, Volpiansky, Clements, \& Ball, 2007). Technical assistance in support of the implementation of a MTSS model is multifaceted and includes training and ongoing consultation in the conceptual, methodological, and practical aspects of MTSS and the systemic change factors that influence the process of implementing any new innovation (Kratochwill et al., 2007). An emphasis on developing capacity to support educators in their implementation of MTSS is key to an understanding of the high quality technical assistance needed to support system change (Glover \& DiPerna, 2007).

Given the critical role technical assistance plays in promoting the implementation of new innovations, technical assistance centers have been established on national, state, and local levels for a variety of initiatives. The National Technical Assistance Center on Positive Behavioral Interventions and Supports (PBIS) was established by the U.S. Department of Education, Office of Special Education Programs to provide schools and school districts with capacity-building information and technical assistance for the identifying, adopting, and sustaining school-wide PBIS/MTSS. The Blueprint for School-Wide Positive Behavior Support Training and Professional Development (Lewis, Barrett, Sugai, \& Horner, 2010) was put forth by the National Technical Assistance Center on PBIS to guide schools, school districts, and regional/state level practitioners and technical assistance providers in designing evidence-based professional development for school-wide PBIS implementation. The essential features of professional development for school-wide PBIS includes (a) skill sets or knowledge trainers and coaches must master, (b) recommended professional development delivery or activities, (c) targets of school team training, and (d) measurable intended outcomes (Lewis et al., 2010). To build capacity for implementation across multiple levels of schools, school districts, and states/regions, professional development must encompass individuals who can serve capably in the roles of district coordinators, trainers, and technical assistance providers that are both internal and external to the school building. The expected content knowledge for technical assistance providers, according to the Blueprint for School-Wide Positive Behavior Support Training and Professional Development is presented in Table 1. For an integrated model addressing behavior and academic supports, the expected content knowledge for technical assistance providers would also include: (a) Knowledge of the core Response to Intervention principles and components; (b) Knowledge and skills necessary for using the core (Tier 1) curricula with $100 \%$ implementation accuracy; (c) Skills for administration, scoring, and interpretation of benchmarks for basic academic skills; (d) Knowledge and skills necessary for using the Tier 2 instructional materials with $90 \%$ or better implementation accuracy, and (e) Knowledge and skills necessary for weekly progress monitoring of students receiving Tier 2 instruction (Brown-Chidsey \& Steege, 2005). It is recommended that state and regional cooperatives engage in a self-assessment process to determine their ability to provide training and technical assistance to support district implementation of a multi-tiered system of support (Lewis et al., 2010). 
Table 1. Expected Content Knowledge for Technical Assistance Providers of School-wide PBS

\begin{tabular}{|c|c|}
\hline $\begin{array}{l}\text { Content Knowledge } \\
\text { Pertaining to Universal } \\
\text { (Tier I) Supports }\end{array}$ & $\begin{array}{l}\text { - } \quad \text { Multiple data collection systems } \\
\text { - } \quad \text { Sroblem solving with data } \\
\text { - } \quad \text { Effective Instruction } \\
\text { - } \quad \text { Rulassroom management } \\
\text { - } \quad \text { Model school examples } \\
\text { - } \quad \text { Basics of Applied Behavior Analysis } \\
\text { - } \quad \text { Meetings/Team roles } \\
\text { - } \quad \text { Communication within building } \\
\text { - } \quad \text { Targeted technical assistance } \\
\text { - } \quad \text { Task analyze team generated universal practices for implementation } \\
\text { Codify practices into policy }\end{array}$ \\
\hline \begin{tabular}{lll} 
Content & \multicolumn{2}{c}{ Knowledge } \\
Pertaining to Tier & II \\
and Tier III Supports &
\end{tabular} & 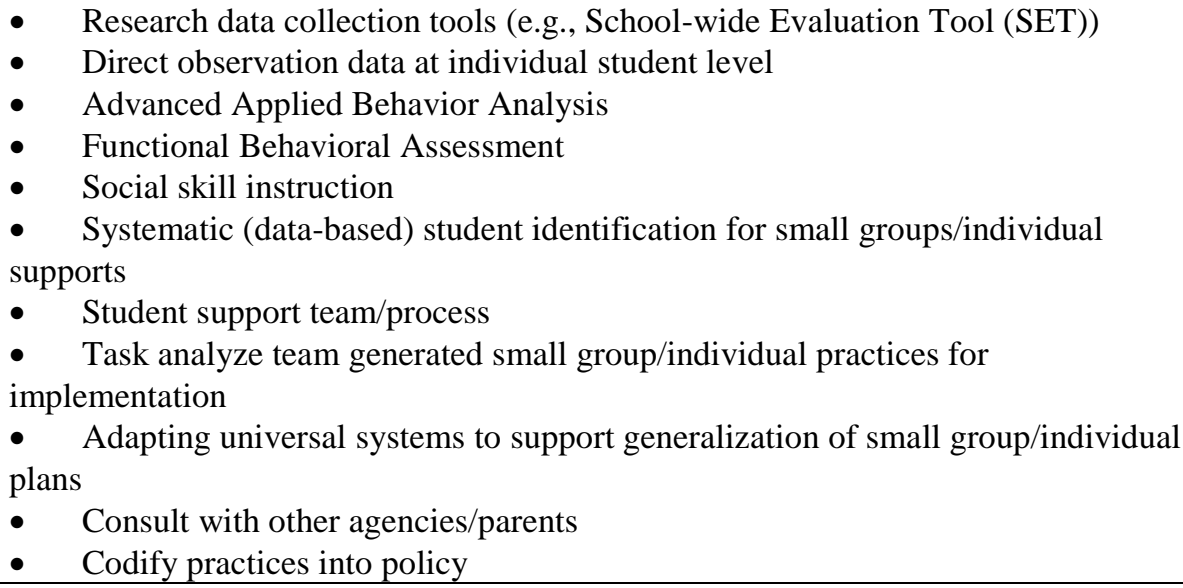 \\
\hline
\end{tabular}

Source: Blueprint for School-Wide Positive Behavior Support Training and Professional Development (Lewis et al., 2010, pp. 28-29)

\subsection{The Instructional Hierarchy Model}

The Instructional Hierarchy model (Table 2) outlines the stages that an individual progresses through when learning a new skill, as well as, the changes in instructional practices that should accompany each stage of learning (Haring \& Eaton, 1978). The four stages include: (a) acquisition, (b) fluency, (c) generalization, and (d) adaptation. Skill acquisition reflects the foundational knowledge and skills of a technical assistance provider previously identified in Table 1. Technical assistance providers demonstrate fluency when they are able to apply the foundational knowledge and skills accurately and link practitioners to resources in a fluid, expeditious manner. Generalization involves the skill proficiency needed to apply the foundational skills to a variety of settings and circumstances. Generalization for a technical assistance provider might include the ability to problem solve "on the fly" when recognizing that a school district is struggling with a particular aspect of service delivery.

Table 2. The Instructional Hierarchy (Haring \& Eaton, 1978)

\begin{tabular}{ll}
\hline Acquisition & $\begin{array}{l}\text { Individual has begun to learn how to complete the target skill correctly, but is not yet } \\
\text { accurate or fluent in skill use. }\end{array}$ \\
Fluency & Individual is able to complete the target skill accurately, but works slowly. \\
Generalization & $\begin{array}{l}\text { Individual is accurate and fluent in using the target skills, but does not typically use it } \\
\text { in different settings or circumstances. }\end{array}$ \\
Adaptation & $\begin{array}{l}\text { Individual is accurate and fluent in using the skill and is able to use the skill in many } \\
\text { settings and circumstances. However, the individual is not yet able to modify or adapt } \\
\text { the skill to fit novel task demands or situations. }\end{array}$ \\
\end{tabular}


Adaptation involves the technical assistance provider's ability to initiate modifications to MTSS implementation to meet the demands of a unique local context (e.g., different school environment, student demographics, availability of resources, etc.). Mutual adaptation, or modifying aspects of the initiative to fit the local context, might also yield benefits, in contrast to an emphasis on replication, in which scaling up (i.e., increasing the number of schools involved in the initiative) occurs without regard for the local context (Coburn, 2003; Datnow, Hubbard, \& Mehan, 2002; Hubbard \& Mehan, 1999; Stringfield \& Datnow, 1998).

Understanding skill proficiency within this learning hierarchy informs the design of organizational supports required to advance targeted skills to the next stage. For example, during the initial acquisition stage, instructional procedures should utilize demonstration, modeling, and cueing in combination with performance feedback (Haring \& Eaton, 1978). Practice is essential for skill development at the fluency stage, with research indicating that at least $70 \%$ of the allotted instructional time be devoted to skill practice (Binder, 1996). Building generalization involves structured opportunities to practice the skill over time, across a wide variety of possible settings and circumstances, and with the expectation that other related skills may also be strengthened (Stokes \& Baer, 1977). Adaptation requires skill proficiency and knowledge of the relevant content, contexts, and processes in order to identify the core elements of a skill and modify its use in response to novel settings and situations (Haring \& Eaton, 1978). Facilitating adaptation involves guidance and specific feedback regarding the type and degree of modifications permissible within the parameters of implementation fidelity.

Given that technical assistance providers serve to promote knowledge and skill acquisition, fluency, and generalization among the practitioners they support, the technical assistance providers have already achieved skill acquisition, fluency, and generalization relevant to the knowledge and skills they promote. The most advanced level in the Instructional Hierarchy, however, presents unique challenges for technical assistance providers as they seek to adapt established content and skills to fit novel situations.

\section{Method}

\subsection{Participants and Setting}

The participants for this study included 10 of the 10 Technical Assistance Providers (TAPs) who served in Michigan's Integrated Behavior and Learning Support Initiative (MiBLSi) in Year 1 of the study. The participants included 9 females and 1 male. All of the participants were White. A resume review conducted for a parallel study indicated the majority of the TAPs (57\%) had a professional background as school psychologists, followed by special educators (29\%), and a reading specialist (14\%) (VanDeusen-MacLeod, 2013). Six of the TAPs also submitted an independent written response as part of the verification process, for a response rate of $60 \%$. All 10 of the TAPs participated in the focus group conducted at the end of the study for the purposes of debriefing and further verification. In Year 2, 9 of the 10 TAPs continued in their role as a technical assistance provider for the initiative. In this second year of the study, 9 of the 9 remaining TAPs (100\%) participated in the individual telephone interviews, verification process, and focus group. The Year 2 participants included 8 females and 1 male. All of the participants were White.

\subsection{Research Design and Procedures}

This study employed a descriptive research design using qualitative data gathered in two phases to compile, summarize, and verify the perceptions of the TAPs regarding their organization's structure and function and their professional development needs. In the first phase of data collection, individual interviews were conducted by an external evaluator via telephone. The interview questions were provided to the TAPs in advance of the scheduled interview. TAPs were also provided assurances that their individual responses would remain anonymous and their confidentiality would be preserved. In the second phase of data collection, the TAPs were given a written summary of the individual telephone interview transcripts and asked to verify the summary by providing a written response. Focus groups were conducted by the external evaluator with the TAPs and separately with members of two other units within the organization (i.e., Professional Learning Unit, Evaluation and Research Unit) to elicit responses to the summary generated by the interviews and verification process. This two-phase data collection process first implemented in Year 1 was replicated in Year 2, with one exception. In Year 2, the TAPs asked to provide one collective written response as part of the verification process rather than submit individual, independent responses as they did in Year 1.

\subsection{Measures and Analyses}

Telephone Interview Protocols: Year 1 and Year 2. The semi-structured telephone interview protocol for Year 1 was comprised of two open-ended questions: (a) "What expectations did you have for the new organizational structure in terms of your role, your work, and the roles and responsibilities of others?" and (b) "How have your actual experiences pertaining to your role and work compared to your expectations for your role and work within the new organizational structure? How well is the structure working?" The semi-structured interview protocol for Year 2 was comprised of four 
open-ended questions: (a) What are the greatest successes of MiBLSi this year?" (b) "How well does your unit, the Technical Assistance Unit function?" (c) "From your perspective, how well do the Professional Learning Unit, Evaluation \& Research Unit function? Describe the level of collaboration between the units." (d) "What are some of the areas of needed improvement to make MiBLSi more effective and more efficient?"

Verification Process Prompt. The verification process included a statement regarding the major themes emerging from the synthesis of the telephone interviews, followed in Year 1 by the prompt: "To what degree do you judge each of these factors to be an obstacle to the MiBLSi mission to promote a Multi-Tiered System of Support at the district level? In other words, which of these factors do you consider to be obstacles and why? Which of these factors are not obstacles based on your experiences and why?" The results of the data compilation and verification process were then shared in a focus group structure to elicit clarification and elaboration. In Year 2, the TAPs were presented with the major themes emerging from a synthesis of the telephone interview data and asked to respond to the following prompt: "To what degree do you agree with the content and tone reflected in the Summary and why?

Are there any additional insights you could share to elaborate on, clarify, or refine the information provided in the Summary?"

Content analysis was used to analyze qualitative data obtained from telephone interviews and written responses provided by the TAPs. Through content analysis, key concepts reflecting emerging themes were identified and coding categories were generated (Patton, 2002). Through the coding process, qualitative data were sorted and defined into categories. Codes were defined and redefined throughout the analysis process as themes emerged. Analyst triangulation, involving the use of two individuals independently analyzing the same qualitative data and comparing their findings, was used to ensure the credibility of both the procedures and the conclusions.

\section{Results}

Three themes emerged from the needs assessment process conducted with the TAPs across both Year 1 and Year 2. The three themes included: (a) structures and processes for communication and problem solving, (b) clarifying the roles of the TAP within the organization, and (c) promoting fidelity of implementation among diverse school districts by balancing implementation fidelity and customization.

\subsection{Structures and Processes for Communication and Problem Solving}

Structures and processes for effective, timely communication in support of problem solving emerged as a primary theme in Year 1 and 2. Through the structured needs assessment process, TAPs expressed an interest in (a) increasing two-way communication between the content developers and the TAPs, (b) formalizing a process for the provision of feedback when a need is identified in the field, and (c) increasing peer-to-peer communication among the TAPs to share ideas (i.e., "What are things you are doing to support districts?") and resolve challenging situations.

\subsection{Clearly Defined Roles of Technical Assistance}

In many organizations, technical assistance providers play crucial roles in translating the knowledge they helped develop into practice in applied settings. Yet, within an organization where technical assistance providers are not also part of the development of the content knowledge it delivers, a certain degree of the provider's professional autonomy may be lost. TAPs participating in the structured needs assessment expressed a lack of clarity about their role and the sense that their contribution to the initiative were diminished for not having an opportunity to shape the content knowledge focus of their technical assistance. A primary theme among the TAPs was a recognition that their professional identity and potential contributions to shaping content knowledge and its diffusion was short-changed by a lack of clarity surrounding their role in initiating, revisiting, and revising content modules to best serve practitioners' needs. In both Year 1 and Year 2, TAPs acknowledged on-going efforts to clarify the roles and responsibilities of individuals within the organization and to bridge a potential divide between the content development and technical assistance units. The primary recommendation emerging from the needs assessment process was to create opportunities for TAPs to engage in a productive dialogue regarding their role in identifying innovative strategies to match complex content knowledge to the most effective form of delivery to meet the diverse needs of consumers at all levels with respect to content, context, and process.

\subsection{Promoting Fidelity of Implementation Among Diverse School Districts by balancing Implementation Fidelity and Customization}

The final theme emerging from the needs assessment process was a need for greater clarity regarding the balance between implementation fidelity and customization. Intensive Technical Assistance was defined by Fixsen, Blase, Horner, and Sugai (2009) as the technical assistance provider taking, "responsibility for providing information and necessary supports and for doing whatever it takes to assure intended outcomes occur in a timely and effective manner" (p. 1). Attending to the local context is critical to the technical assistance provider's role in supporting the attainment of 
intended outcomes through promoting the implementation of a standard model. As part of the structured needs assessment process, several TAPs shared that this tension between contextualizing a MTSS for local implementation and the need to preserve the fidelity of implementation put them at odds with an unwavering focus on implementation fidelity. Balancing the tension between fidelity to the model and the realities of the local capacity for systems change is one of the most challenging aspects of technical assistance. Through the needs assessment process, TAPs expressed a desire for dialogue and decision rules regarding levels of acceptable variation in implementation warranted at each stage of implementation to meet the individualized conditions within each school district. Equipped with a more explicit, data-driven understanding of what constitutes appropriate customization, TAPs would be able to maximize their vantage points of being closest to the front line of implementation to bridge the gap between research and practice.

Taken together, the results of the structured needs assessment identified four recommendations for strengthening organizational structures and processes to support and sustain effective technical assistance (See Table 3). A call for strengthening communication structures and processes (i.e., collaboration, feedback, structured problem solving, and peer consultation) is common among all four recommendations.

Table 3. Organizational Structures and Processes to Support Effective Technical Assistance

I. Increase communication and collaboration between content developers and technical assistance providers (i.e., the engineers that design the plane and the pilots who fly it).

II. Formalize a process for the provision of feedback from the technical assistance providers and the rest of the organization

III. Establish a structured problem-solving process data-driven decision rules regarding levels of acceptable variation in implementation warranted at each stage of implementation to meet the individualized conditions within each school district.

IV. Increase peer consultation (i.e., professional learning communities or networks) among technical assistance providers to share locally-determined solutions, resolve challenging situations, and clarify the professional role of a technical assistance provider in supporting implementation to meet the diverse needs of consumers with respect to content, context, and process.

In sum, the results of the study indicated the need for structures and processes for communication and problem solving, greater clarity regarding the roles of the TAP within the organization, and additional guidance in balancing implementation fidelity and customization. Through the needs assessment process, the TAPs described possible solutions and/or ideal practices that formed the basis of four recommendations. Although the four recommendations specifically address the needs identified by the TAPs in this initiative, they have relevance to the structures and processes needed to support technical assistance in a wide range of initiatives.

\section{Discussion}

Several theories exist to describe the processes by which knowledge leads to action in applied settings. Knowledge-for-action theories include theories that: (a) anticipate the knowledge will be altered based on the local context (translation theory), (b) predict practitioner behaviors will to lead to alternative, adapted skills (transfer theory), and (c) emphasize the spread of knowledge, which may or may not lead to changes in practitioner behaviors (diffusion theory) (Ottoson, 2009). In contrast, implementation theory posits a one-way, top-down movement of knowledge with high-fidelity practitioner behaviors as the intended outcome. Implementation theory recognizes that contextual differences and influences will shape the movement of knowledge to action, but the core components of the innovation will need to be implemented with fidelity (Fixsen, Naoom, Blase, Friedman, \& Wallace, 2005). Technical assistance plays a critical role in promoting high-fidelity practitioner behaviors as informed by implementation theory and research.

Despite recent advancements in the prominence of technical assistance, in the form of on-going, site-based training, coaching, and consultation within education, very little is known about support needed to maximize the effectiveness of technical assistance providers. This study examined the self-identified organizational supports needed for technical assistance providers serving a state-wide multi-tiered system of support initiative (MTSS) using the Instructional Hierarchy model as a conceptual framework. The Instructional Hierarchy model provided a reasonable fit given that technical assistance providers have recognized expertise that would be reflected in mastery of the acquisition, fluency, and generalization stages of the hierarchy. Although advancements in the field (e.g., promising practices, information 
technology) may require technical assistance providers need to acquire new skills, providers generally have the knowledge and skills needed to support high-fidelity practitioner behaviors within their initiative. The challenge inherent in technical assistance, therefore, rests in adaptation. This study sought to better understand the challenge of adaptation within technical assistance and the organizational structuress and processes needed to promote effective adaptation.

The results of the needs assessment yielded three major themes that persisted as challenges across Years 1 and 2: (a) structures and processes for communication and problem solving, (b) clarifying the role of the TAP, and (c) promoting fidelity of implementation among diverse school districts by balancing implementation fidelity and customization. Using the instructional hierarchy as a conceptual framework, these three themes reflect challenges of adaptation. Adaptation requires skill proficiency and knowledge of the relevant content, contexts, and processes in order to identify the core elements of a skill and modify its use in response to novel settings and situations (Haring \& Eaton, 1978). Whereas replication involves the high fidelity adoption of an innovation with little or no allowance for modest modifications, mutual adaptation in a systems change context, involves the use of slight modifications to the innovation to optimize the fit within the local context (Coburn, 2003; Datnow et al., 2002; Hubbard \& Mehan, 1999; Stringfield \& Datnow, 1998). Adaptation presents tremendous challenges for technical assistance providers promoting fidelity of implementation among diverse school districts.

As a result of this needs assessment process, technical assistance providers described possible solutions and/or ideal practices. These self-generated recommendations focused on organizational structures and processes to increase effective communication across the organization and among the technical assistance providers. Although the recommendations for increased collaboration, feedback, a structured problem-solving process with data-driven decision rules, and peer consultation specifically address the needs identified by the technical assistance providers in this initiative, the recommendations have relevance to the structures and processes needed to support technical assistance in a wide range of initiatives.

The results of this study also have implications for the practice of adaptation in MTSS implementation. The balance between implementation fidelity and customization is central to MTSS implementation efforts nationally. Clearly implementation fidelity is critical. From the academic and behavior intervention research, it is generally recognized that lower levels of intervention fidelity undermine the effectiveness of the intervention (Sanetti \& Kratochwill, 2009). However, the degree to which differences in intervention fidelity impact intervention outcomes is unknown and likely specific to a particular intervention (Sheridan, Bovaird, Glover, Garbacz, Witte, \& Kwoon, 2012). Previous research indicates that even partial success in completing intervention components can produce the desired intervention outcome, depending on the intervention and its unplanned modifications (Gilbertson, Witt, LaFleur Singletary, \& VanDerHeyden, 2007; Northup, Fisher, Kahang, Harrell, \& Kurtz, 1997).

Fidelity of implementation will also be influenced by the stage of implementation a school district is in on the continuum ranging from exploration to installation to initial implementation to full implementation of the initiative (Fixsen et al., 2005). Technical assistance providers must discern a school district's stage of implementation in order to adapt their support to meet district needs, with more emphasis on high fidelity of implementation in the earlier stages of implementation, greater latitude in customization for districts in more advanced stages of implementation, and the ability to provide differentiated technical assistance throughout the continuum. Effective, differentiated technical assistance is reliant on providers being highly-skilled in adaptation.

As applied to a state-wide MTSS initiative, striking the balance between fidelity and local customization will require a structured problem-solving process and a series of decision rules for contextualizing implementation. Data-driven decision rules would be informed by co-plotting measures of implementation fidelity with targeted outcome measures to determine if the degree of implementation achieved is sufficient for the attainment of the goal or benchmark.

From the academic and behavior intervention literature, the process of balancing fidelity and customization could also involve listing all of the elements of implementation at a particular level (school, district, state regional support) and then distinguishing among these elements those that are core elements (i.e., non-negotiable) that constitute the initiative and that without which would sacrifice its effectiveness. Those that are negotiable could be modified slightly if needed (Hawkins, Morrison, Musti-Rao, \& Hawkins, 2008). Separately, a list of deal breakers, the undesirable activities or conditions that reduce the effectiveness of the initiative, would need to be identified.

The two implications of this study, the application of the Instructional Hierarchy to focus on the challenge of adaptation and the resulting need for organizational structures and processes to increase communication (e.g., collaboration, problem solving, peer consultation), offer unique contributions to the future practice of technical assistance. Despite the current national prominence of technical assistance for embedded and sustained professional development, very little attention has been given to the needs of technical assistance providers and the organizational structures and processes 
needed to sustain effective technical assistance. Without the organizational supports needed to address the challenges of adaptation, technical assistance will not have the intended impact and capable technical assistance providers may not persist in their efforts to promote change. Effective and sustainable technical assistance requires initiatives institutionalize organizational structures and processes to provide support to those that support others.

This study has one primary limitation that must be taken into account when interpreting the findings. The results were based on the verbal and written responses of 10 individuals serving as technical assistance providers in one state-wide initiative. As such, the small sample size places restriction on the generalizability of the results. The technical assistance providers in this study served in a wide variety of settings within Michigan, which included urban Detroit and the sparsely populated Upper Peninsula. Given the diversity of settings in which the TAPs worked, this purposive sample, inclusive of all TAPs in the state-wide initiative, provided insight into the challenges of the provision of technical assistance, which may generalize to other states' efforts to promote MTSS.

As with any multi-layered initiative, the evolving nature of the initiative itself dictates that professionals within the organization function at a very high level of competency in complex applied setting with considerable independence. The instructional hierarchy has utility in understanding the organizational supports needed to maximize the impact of technical assistance providers. Given the complexity of promoting MTSS across unique school, district, and regional state support systems, organizational structures and processes for supporting the efforts of technical assistance providers is key to achieving implementation outcomes and realizing a true impact on student learning and behavior outcomes.

Building an effective, impactful, and sustainable system for technical assistance requires that the same intensity of focus on meeting the needs of practitioners be applying to meeting the needs of the technical assistance providers. The application of the Instructional Hierarchy to the practice of technical assistance acknowledges the advanced skills of technical assistance providers within their initiative, while recognizing the challenges of adaptation in often complex, uncharted, and diverse school systems. In this study, a structured needs assessment process resulted in three needs reflecting the challenges of adaptation along with four recommendations for improving organizational structures and processes to address these needs. This study extends the research literature on technical assistance by focusing on improving supports for technical assistance providers.

\section{Acknowledgements}

The authors wish to acknowledge all of the technical assistance providers who shared their insights as part of the structured needs assessment process, Steve Goodman and Anna Harms for their guidance and feedback throughout the process, and Elizabeth VanDeusen-MacLeod for her foundational research on technical assistance within the initiative.

\section{References}

Algozzine, B., Horner, R. H., Sugai, G., Barrett, S., Dickey, S. R., Eber, L., Kincaid, D., et al. (2010). Evaluation blueprint for school-wide positive behavior support. Eugene, OR: National Technical Assistance Center on Positive Behavior Interventions and Support. Retrieved from www.pbis.org

Binder, C. (1996). Behavioral fluency: Evolution of a new paradigm. The Behavior Analyst, 19 (2), 163-197.

Brown-Chidsey, R., \& Steege, M. W. (2005). Response-to-intervention: Principles and strategies for effective practice. New York: Guilford Press.

Coburn, C. E. (2003). Rethinking scale: Moving beyond numbers to deep and lasting change. Educational Researcher, 32(6), 3-12. http://dx.doi.org/10.3102/0013189X032006003.

Daly, E. J. III, Martens, B. K., Barnett, D., Witt, J. C., \& Olson, S. C. (2007). Varying intervention delivery in response-to-intervention: Confronting and resolving challenges with measurement, instruction, and intensity. School Psychology Review, 36, 562-581.

Datnow, A., Hubbard, L., \& Mehan, H. (2002). Extending educational reform: From one school to many. London: Routledge/Falmer.

Fixsen, D. L., Blase, K. A., Horner, R., \& Sugai, G. (2009, February). Intensive technical assistance. Scaling Up Brief \#2. Chapel Hill: The University of North Carolina, FPG, SISEP.

Fixsen, D. L., Naoom, S. F., Blase, K. A., Friedman, R. M. \& Wallace, F. (2005). Implementation Research: A Synthesis of the Literature. Tampa, FL: University of South Florida, Louis de la Parte Florida Mental Health Institute, The National Implementation Research Network (FMHI Publication \#231).

Gilbertson, D., Witt, J. C., LaFleur Singletary, L., \& VanDerHeyden, A. (2007). Supporting teacher use of interventions: Effects of response dependent performance feedback on teacher implementation of a math intervention. Journal of Behavioral Education, 16, 311-326. http://dx.doi.org/10.1007/s10864-007-9043-0 
Glover, T., \& DiPerna, J. C. (2007). Service delivery for response to intervention: Core components and directions for future research. School Psychology Review, 36(4), 526-540.

Haring, N. G., \& Eaton, M. D. (1978). Systematic procedures: An instructional hierarchy. In N. G. Haring, T. C. Lovitt, M. D., Eaton, \& C. L. Hansen (Eds.), The fourth R: Research in the classroom. Columbus, OH: Charles E. Merrill Publishing Company.

Hawkins, R. O., Morrison, J. Q., Musti-Rao, S., \& Hawkins, J. A. (2008). Treatment integrity for academic interventions in real world settings. School Psychology Forum: Research in Practice, 2(3), 1-15.

Hubbard, L., \& Mehan, H. (1999). Scaling up an untracking program: A co-constructed process. Journal of Education for Students Placed at Risk, 4(10), 83-100. http://dx.doi.org/10.1207/s15327671espr0401_6

Individuals with Disabilities Education Improvement Act of 2004, 20 U.S.C. $1400 \S$ et seq. (2004).

Kratochwill, T. R., Volpiansky, P., Clements, M., \& Ball, C. (2007). Professional development in implementing and sustaining multitier prevention models: Implications for response to intervention. School Psychology Review, 36(4), 618-631.

Lewis, T.J., Barrett, S., Sugai, G., \& Horner, R. H. (2010). Blueprint for schoolwide positive behavior support training and professional development. Eugene, OR: National Technical Assistance Center on Positive Behavior Interventions and Support. Retrieved from www.pbis.org

No Child Left Behind Act of 2001. (Public Law 107-110).

Northup, J., Fisher, W., Kahang, S. W., Harrell, R., \& Kurtz, P. (1997). An assessment of the necessary strength of behavior treatments for severe behavior problems. Journal of Developmental and Physical Disabilities, 9(1), 1-16. http://dx.doi.org/10.1023/A:1024984526008.

OSEP Center on Positive Behavioral Interventions and Supports. (2009). What is School-wide Positive Behavioral Interventions and Supports. Eugene, OR: Author. Available: www.PBIS.org.

Ottoson, J. M. (2009). Knowledge-for-action theories in evaluation: Knowledge utilization, diffusion, implementation, transfer, and translation. In J. M. Ottoson \& P. Hawe (Eds.), Knowledge utilization, diffusion, implementation, transfer, and translation: Implications for evaluation. New Directions for Evaluation, 124, 7-20. http://dx.doi.org/10.1002/ev.310

Patton, M. Q. (2002). Qualitative research and evaluation methods ( $3^{\text {rd }}$ Edition). Thousand Oaks, CA: Sage.

Sanetti, L. M. H., \& Kratochwill, T. R. (2009). Treatment integrity assessment in the schools: An evaluation of the treatment integrity planning protocol. School Psychology Quarterly, 24, 24-35. http://dx.doi.org/10.1037/a0015431

Sheridan, S. M., Bovaird, J. A., Glover, T. A., Garbacz, S. A., Witte, A., \& Kwoon, K. (2012). A randomized trial examining the effects of conjoint behavioral consultation and the mediating role of the parent-teacher relationship. School Psychology Review, 41(1), 23-46.

Stokes, T. F., \& Baer, D. M. (1977). An implicit technology of generalization. Journals of Applied Behavior Analysis, 10(2), 349-367. http://dx.doi.org/10.1901/jaba.1977.10-349

Stringfield, S., \& Datnow, A. (1998). Scaling up school restructuring designs in urban schools. Education and Urban Society, 30(3), 269-276. http://dx.doi.org/10.1177/0013124598030003001

Sugai, G., \& Horner, R. H. (2009). Responsiveness-to-Intervention and School-Wide Positive Behavior Supports: Integration of multi-tiered system approaches. Exceptionality, 17, 223-237. http://dx.doi.org/10.1080/09362830903235375

Turnbull, B.J., White, R.N., Sinclair, E., Riley, D.L., \& Pistorino, C. (2011, August). National Evaluation of the Comprehensive Technical Assistance Centers: Final Report (NCEE 2011-4031). Washington, DC: National Center for Education Evaluation and Regional Assistance, Institute of Education Sciences, U.S. Department of Education.

VanDeusen-MacLeod, E. (2013). Understanding the Work of Technical Assistance Providers in School Reform. Presentation at the Michigan's Behavior and Learning Support Initiative (MiBLSi) Higher Education Learning Partners Conference, Bath, MI.

\section{(cc) BY}

This work is licensed under a Creative Commons Attribution 3.0 License. 